\title{
Referral and counter-referral system between secondary and tertiary care facilities in a children's hospital network of Greater Buenos Aires
}

\author{
Pablo García Munitis, M.D., ${ }^{a}$ Maximiliano de Abreu, M.D. ${ }^{b}$ Laura Antonietti, M.D. ${ }^{b}$ \\ Mercedes Guillén, B.S., ${ }^{c}$ Matías Said, B.S., César Montali, M.D., ${ }^{a}$ \\ Natalia Arrospide, M.D. , ${ }^{a}$ Guillermo Barbero, M.D., ${ }^{a}$ Diego Cerrudo, M.D. ${ }^{e}$ \\ Estela Parodi, B.S. ${ }^{d}$ Cinthia Amato, B.S. ${ }^{e}$ and Marcelo Pereyra, M.D. ${ }^{a}$
}

\begin{abstract}
Introduction. Hospital El Cruce is a tertiary care facility which is part of a healthcare network that has been operating since July 2008 and includes health centers from five municipalities of the South of Greater Buenos Aires.

The objective of the study was to describe the referral and counter-referral system at the pediatric intermediate medical care unit of the Hospital El Cruce, the tertiary level care of the network, and secondly to identify the critical points that could go against the consolidation of the network and to analyze the level of knowledge about it.
\end{abstract}

Population and Methods. This was a crosssectional, prospective study conducted at the pediatric intermediate medical care unit of Hospital El Cruce between July 2008 and December 2010. Indicators related to patient admission and discharge were analyzed. A survey was administered to all the heads of the network's pediatric departments in order to assess the level of knowledge they had about it. Results. A total of 1677 patients werehospitalized; $83.9 \%$ were referred from the network. Of all referrals made, $71.1 \%$ were accepted. There were 156 patients $(9.4 \%)$ who were counter-referred to the referring facility. The survey results showed that $70 \%$ of heads of pediatric departments were unaware of the range of services provided by the network.

Conclusions. Health care exchange was predominantly based on accepting patients referred from secondary care facilities to Hospital El Cruce and a minimum number of counterreferrals to referring facilities, with a radial pattern dynamics. There was scarce knowledge about the availability of the network health service delivery.

Key words: referral, continued care, tertiary care facilities, comprehensive health networks.

http:/ /dx.doi.org/10.5546/aap.2013.405

\section{INTRODUCTION}

The purpose of a network health system is to improve the effectiveness of healthcare services through a comprehensive care approach.
It constitutes a novel healthcare model which implies the challenge of overcoming the system's fragmentation by providing coordinated care. ${ }^{1,2}$

Health networks tend to the association among healthcare facilities, giving place to a level of effectiveness and cooperation that would be hard to achieve through other mechanisms. Such development implies spanning across institutions and individuals; it starts with the knowledge of the parties involved and the path patients take once they enter the network, and requires a highly complex coordination of care. To date, this type of coordination has been assessed using different strategies and tools, and its optimization is a priority for health systems. ${ }^{1-4}$

Historically, healthcare in the Southeast of Greater Buenos Aires has been shaped around secondary care hospitals, resulting in a need to have a hospital that would be able to deal with tertiary care requirements. The tertiary care network of Hospital El Cruce (HEC) started operating in June 2008, based on a work concept of coordinating capacities between the region's hospitals and the HEC, operating in a network of complementary services. The HEC is located at an equal distance from the rest of the secondary care hospitals (Mi Pueblo, at Florencio Varela; Evita Pueblo, at Berazategui; Dr. Iriarte, at Quilmes; Dr. Oller, at Solano; Dr. Oñativia, at Almirante Brown; and Dr. Lucio Meléndez, at Adrogué), in an 
area that comprises five municipalities, with one third of their approximately 1800000 inhabitants in the pediatric age group. ${ }^{4}$

The HEC is part of a national, segmented health system where three subsectors co-exist: the public, private, and social security subsectors. These are distributed in 24 health systems (corresponding to the 23 provinces and the Autonomous City of Buenos Aires) which usually are not enough to meet the population's health needs and whose most relevant characteristic is an unequal access to services. ${ }^{5,6}$

The HEC is an innovative experience in the region and was conceived as part of a public health network composed of the secondary care hospitals mentioned above, which depend on provincial structures, and of 153 primary care facilities, which depend on municipal governments. ${ }^{4}$

The main purpose for creating a Department of Pediatrics within the HEC was to meet the needs of children with critical or complex conditions living in this region. The pediatric hospitalization service is made up of a pediatric intensive care unit (PICU) and a pediatric intermediate medical care unit (PIMCU). The PIMCU was opened in July 2008, and its main objective was to admit patients from the PICU. At the beginning, the PIMCU had 10 beds, and by March 2009, it was fully operational with 20 beds available.

The PIMCU provides care for patients with conditions that cannot be managed at primary and secondary care facilities in the region, and who have highly variable discharge diagnoses as a result of availability in the PICU and the availability of certain pediatric subspecialties (cardiology, cardiovascular surgery, neurosurgery, infectious diseases, endoscopy, neurology, nephrology, oncology, orthopedics, and general surgery).

The HEC's sphere of influence has started a process of network development and sense of belonging. The HEC's management is targeted at a continuous search for improvements at a healthcare and organization level.

The first step in the process is to know the aspects related to the exchange and integration of healthcare between the network's different facilities in order to develop common policies and consensus regarding the varying responsibilities and goals. ${ }^{2,4}$

\section{OBJECTIVES}

The main objective of this study was to describe the referral and counter-referral system at the PIMCU of Hospital El Cruce, the tertiary level care of the network.

Secondary objectives included the identification of the critical points in the referral and counter-referral process that could go against the network consolidation and to analyze the knowledge of the pediatric network among the heads of the pediatric departments.

\section{POPULATION AND METHODS}

Design: observational and prospective study conducted at the HEC's PIMCU from July 2008 to December 2010.

The tool used for recording, saving and recovering all data obtained from the healthcare process was an electronic medical record, which has been used since the hospital started working.

Support was obtained from the Patient Management, IT, and Statistics Departments. Information on referrals between other lower care facilities was obtained.

When the HEC's Department of Pediatrics started operating, the network had no structure indicators: common clinical practice guidelines, healthcare maps, a single medical record template, a universal referral, counter-referral and discharge form, a "list of available pediatric services" that would include all the network's providers, and criteria regarding patient admission, counter-referral to and discharge from the PIMCU.

Population: all medical records corresponding to patients aged from 1 month to 18 years old and admitted to the PIMCU were included. Personal data, diagnosis (ICD 10), patient origin, and condition at discharge (whether patients were discharged or counter-referred to the referring hospital) were obtained.

For the analysis of healthcare exchange at the PIMCU, indicators related to patient admission and discharge were assessed. Such indicators were developed especially for this study.

Admission: the percentage of referrals accepted over the total referrals made, and the origin of PIMCU admissions (referring department and facility) were determined.

Discharge from PIMCU: the following outcome measures were assessed:

- Condition (discharge or counter-referral).

- Percentage of counter-referrals over the total referrals made, by unit of time.

- Percentage of counter-referrals accepted by referring hospitals over the total counterreferrals made. 
- Percentage of counter-referrals by referring hospital.

- Percentage of referrals/counter-referrals by referring facility (from inside/outside the network).

- Percentage of referrals/counter-referrals between other facilities in the network.

Analysis of knowledge about the network: in order to complement the analysis of the network's key elements, an ad hoc survey on "knowledge" about the pediatric network was administered in 2010 to all the heads of the pediatric departments in each of the six network hospitals and the HEC (see the electronic Annex).

The survey included questions on knowledge about the "list of pediatric services available in the network" (pediatric sub-specialties available for the network's patients) with categorical answer options (yes/ no/unknown). Each head of department surveyed provided an answer for a total of 24 sub-specialty options for each of the seven hospitals, including the one where they worked. The answers provided by each head of department regarding their own hospital were used as reference.

\section{Statistical analysis}

Qualitative variables were expressed as numbers and percentages, and they were compared using contingency tables. The progress of indicators over time (by year) was assessed with the $\chi^{2}$ for trend.

The statistical description and analyzes were done using the Epi-Info 3.5.1 software.

The protocol was approved by the HEC's Scientific Advisory Committee and Research Ethics Committee.

\section{RESULTS}

During the July 2008-December 2010 period, 1677 patients were admitted to the PIMCU.

The percentage of bed occupancy was $26 \%$ in $2008,65 \%$ in 2009 , and $70 \%$ in 2010 , with a 10,41 , and 39 bed turnover for the same periods.

\section{Patient admission and discharge}

Of the 1677 patients admitted to the PIMCU, $1053(62.8 \%)$ were transferred from other hospitals, with a time trend on the rise for the 2008-2009-2010 periods ( $\mathrm{p}$ for trend $<0.00001$ ) (Table 1).

A total of $71 \%$ of referrals made to the PIMCU were accepted (895/1258). Taking into consideration the referrals made from other hospitals, 18/25 (72\%), 323/438 (737\%) and $554 / 795$ (69.7\%) were accepted in 2008, 2009 and 2010 , respectively ( $\mathrm{p}$ for trend $=0.16$ ).

Table 2 shows the data recorded at the time patients were admitted to the PIMCU during the 2008-2010 period by the referring facility.

Since the PIMCU was opened, there was a significant increase in the number of referrals from outside the network $(2.3,18.5$ and $16.3 \%$ in 2008 , 2009 and 2010, respectively; $p$ for trend $=0.03$ ) and a relative, non significant although borderline reduction in the number of referrals from the network's hospitals (53.1, 47.8 and $44.9 \%$ in 2008, 2009 and 2010, respectively; $p$ for trend $=0.06$ ).

A total of 1669 patients were discharged from the PIMCU, and 156 (9.4\%) of them were counterreferred. Of the counter-referrals made, $71.2 \%$ were accepted $(156 / 219)$. The rate of counterreferred patients decreased after the first year (Table 3).

TABLE 1. Patient admission to the Pediatric intermediate medical care unit (2008-2010 period)*

\begin{tabular}{lccc}
\hline & $\mathbf{2 0 0 8} \boldsymbol{n}(\mathbf{\%})$ & $\mathbf{2 0 0 9} \boldsymbol{n}(\mathbf{\%})$ & $\mathbf{2 0 1 0} n \mathbf{( \% )}$ \\
\hline Outpatients or referred from other hospitals & $18(13.8)$ & $323(48.8)$ & $554(62.6)$ \\
From HEC's PIMCU & $110(84.6)$ & $310(46.8)$ & $305(34.5)$ \\
From other HEC's departments** & $2(1.6)$ & $29(4.4)$ & $26(2.9)$ \\
Overall total & $\mathbf{1 3 0}$ & $\mathbf{6 6 2}$ & $\mathbf{8 8 5}$ \\
\hline
\end{tabular}

* Admission of patients to the PIMCU according to the site where they were referred from.

** Day Hospital, Emergency Department, other hospitalization departments.

HEC: Hospital El Cruce.

PIMCU: pediatric intermediate medical care unit.

PICU: pediatric intensive care unit. 
Table 4 shows the condition at discharge by referring facility for the 200-2010 period.

There were no significant differences in the number of counter-referred patients from network hospitals or from outside the network $(\mathrm{p}=0.56)($ Table 4$)$.

Table 5 shows conditions at discharge as per the ICD-10 and the percentage of counter-referrals by diagnosis.

No pediatric referrals between other network

TABLE 2. Admission of patients to the Pediatric intermediate medical care unit according to the referring facilities (2008-2010 period)*

\begin{tabular}{lc}
\hline Referring facility & 2008-2010 $n$ (\%) \\
\hline Facilities from outside the network & $270(16.1)$ \\
HEC & $624(37.2)$ \\
Hospitals within the network & $783(46.7)$ \\
Hospital Zonal de Agudos Mi Pueblo & $279(35.6)^{* *}$ \\
Hospital Zonal General de Agudos Evita Pueblo & $169(21.6)^{* *}$ \\
Hospital Zonal General de Agudos Dr. Isidoro Iriarte & $141(18)^{* *}$ \\
Hospital Subzonal Especializado Materno Infantil Dr. Oller & $103(13.2)^{* *}$ \\
Hospital Zonal General Dr. Arturo Oñativia & $69(8.8)^{* *}$ \\
Hospital Zonal General de Agudos Dr. Lucio Meléndez & $22(2.8)^{* *}$ \\
Overall total & 1677 \\
\hline
\end{tabular}

* The table shows the facility that requested the hospitalization of each of the 1677 patients. Whether patients were first hospitalized in the PIMCU, the PICU or a different department, such hospitalization was requested by a provider of the Hospital El Cruce, a network facility or a site from outside the network.

** These values indicate the percentage of admissions in relation to the total number of admissions made at the network hospitals. HEC: Hospital El Cruce.

PIMCU: pediatric intermediate medical care unit.

TABLE 3. Patients discharged from the Pediatric Intermediate Medical Care Unit by condition (2008-2010 period)

\begin{tabular}{lccc}
\hline Destination & $\mathbf{2 0 0 8}$ & $\mathbf{2 0 0 9}$ & $\mathbf{2 0 1 0}$ \\
\hline Discharge & $68(55.7)$ & $621(94.5)$ & $824(92.6)$ \\
Counter-referral & $54(44.3)$ & $36(5.5)$ & $66(7.4)$ \\
Overall total & 122 & 657 & 890 \\
\hline
\end{tabular}

TABLE 4. Condition at discharge according to the referring facility (2008-2010 period)

\begin{tabular}{lcc}
\hline Referring facility & Discharged $\mathbf{n}(\%)$ & Counter-referred $\mathbf{n}(\%)$ \\
\hline Facilities outside the network & $286(89)$ & $34(11)$ \\
HEC & $588(94)$ & $36(6)$ \\
Network facilitates & $639(88)$ & $86(12)$ \\
Hospital Subzonal Especializado Materno Infantil Dr. Oller & $99(91)$ & $10(9)$ \\
Hospital Zonal de Agudos Mi Pueblo & $243(88)$ & $33(12)$ \\
Hospital Zonal General de Agudos Dr. Isidoro Iriarte & $128(87)$ & $19(13)$ \\
Hospital Zonal General de Agudos Dr. Lucio Meléndez & $14(64)$ & $8(36)$ \\
Hospital Zonal General de Agudos Evita Pueblo & $153(91)$ & $16(9)$ \\
Hospital Zonal General Dr. Arturo Oñativia & $2(100)$ & 0 \\
Overall total & $\mathbf{1 5 1 3 ( 9 1 )}$ & $\mathbf{1 5 6}(\mathbf{9 1})$
\end{tabular}

HEC: Hospital El Cruce. 
hospitals were recorded during the study period.

Knowledge of the Pediatric Network's Healthcare Resources: the seven heads of the pediatric departments completed the survey. The overall analysis indicates that $61.5 \%$ of the answers corresponded to the "unknown" category, while $8.5 \%$ were incorrect. Thirty percent of the answers on healthcare resources available at all facilities were correct. When specifically evaluating the level of knowledge about the HEC's available healthcare resources (the only tertiary care hospital) at secondary care facilities, there were $63.8 \%$ correct answers, $16.6 \%$ incorrect answers, and $19.4 \%$ marked as "unknown." The heads of the Department of Pediatrics at secondary care hospitals showed a better knowledge on the list of services provided at the HEC than those at other health facilities (Table 6).

\section{DISCUSSION}

Intermediate medical care units were developed in order to provide care for patients who require a higher level of care than those hospitalized in the internal medicine unit, but who do not require invasive monitoring. ${ }^{7}$ They are a cost-effective alternative to intensive care units and improve healthcare efficiency.

The main objective of creating a PIMCU was accomplished with the development of a service that allowed to transfer patients from the PICU while simultaneously minimizing the complexity of care received by them, although most patients were admitted without requiring hospitalization in the PICU.

The inclusion of the HEC into the public health system evidenced a pre-existing and unmet requirement for tertiary care, both inside and outside the network. The increasingly number of patients transferred from hospitals that are not formally part of the network has demonstrated the pre-existing requirement from outside the network, while the network's requirement for a PIMCU was evidenced by the need to use the PIMCU as a medical area for referring patients from other network hospitals and not only for transferring patients from the PICU.

TABLE 5. Diagnosis at discharge according to the ICD-10 and percentage of counter-referrals as per diagnosis (2008-2010 period)

\begin{tabular}{lcc}
\hline Diagnosis & Discharged $\mathbf{n}(\mathbf{\%})$ & Counter-referred $\mathbf{n}(\%)$ \\
\hline $\begin{array}{l}\text { Respiratory diseases } \\
\text { Injuries, poisoning and }\end{array}$ & $470(87.3)$ & $68(12.7)$ \\
other consequences of external causes & $229(96)$ & $10(4)$ \\
Diseases of the digestive system & $178(95.7)$ & $9(5)$ \\
Infectious and parasitic diseases & $139(92.6)$ & $12(8)$ \\
Diseases of the nervous system & $102(91)$ & $12(10.5)$ \\
Congenital malformations, deformations and & & $3(3.5)$ \\
chromosomal abnormalities & $84(96.5)$ & $1(0.8)$ \\
Malignancies & $57(98.2)$ & $41(14)$ \\
Others & $254(86)$ & $\mathbf{1 5 6}$ \\
Overall total & $\mathbf{1 5 1 3}$ & \\
\hline
\end{tabular}

TABLE 6. Knowledge on health resources by heads of departments from hospitals within the network

\begin{tabular}{lccc}
\hline & Correct (\%) & Incorrect (\%) & Unknown (\%) \\
\hline Head of hospital 1 & 50 & 12.5 & 36 \\
Head of hospital 2 & 35 & 6.9 & 57.6 \\
Head of hospital 3 & 31.2 & 8.3 & 60.4 \\
Head of hospital 4 & 19.4 & 8.3 & 72.2 \\
Head of hospital 5 & 24.3 & 8.3 & 67.3 \\
Head of hospital 6 & 25 & 9.7 & 65.2 \\
Head of hospital 7 & 25 & 5.5 & 69.4 \\
General average & $\mathbf{3 0}$ & 8.5 & $\mathbf{6 1 . 5}$ \\
\hline
\end{tabular}


The low rate of counter-referrals and the radial operating pattern, together with the low level of knowledge about the network by its members have been identified as the critical points that may hurdle the network consolidation.

The low percentage of counter-referred patients leads to bed over-occupancy at the tertiary care level with conditions that could be managed at a lower level of care. In turn, patient counter-referral in all cases was back to the referring facility, and this evidences a "radial" pattern with no interaction between the hospitals that provide a different level of care.

The reasons for the lack of "counter-referral" can be explained as follows: patients' refusal, problems with the referring facility, with the HEC or with the network. In a previous study on the structure and reasons for demand at the Hospital Garrahan, which could be applied to this study, Varone, et al. concluded that parents tend to believe that their children's condition is worse than what the doctors judge and thus justify their stay in a facility that provides a higher level of care, and that almost half of the cases were not satisfied with the referring level. ${ }^{8}$

Secondary care hospitals in the network sometimes do not have enough beds to receive patients counter-referred back from the HEC. An adequate counter-referral is a key factor in the feedback process between the different departments, and requires an additional effort to become effective, but an important pressure from the system or the low sense of belonging to the network among staff members usually lead to counter-referral not taking place. ${ }^{2,9} \mathrm{At}$ times, counter-referral is also prevented by the unavailability of an ambulance to transfer patients.

Lack of referral between other hospitals demonstrates the radial pattern of operations in the network, with no interaction among lower care level hospitals.

The knowledge about the "other one" in the pediatric network is in general too low and has a pyramidal, non multicenter structuring around the tertiary care facility. As per Rovere, ${ }^{2}$ different levels can be found in the process of network development, and being aware of them helps to organize and monitor the different depths of the network. These levels are: recognition (acceptance of the other), knowledge (requiring knowledge of the other), collaboration (collaborate: work together with), cooperation (joint operation), and partnership (sharing resources). Working on the "knowledge" is key to achieve the network's consolidation. Networking does not work on its own; it is rather the result of likely initiatives, agreements or discrepancies that can be implemented. ${ }^{1-3,10}$ It is a daily action that affects both institutional and personal levels. Rovere underscores that healthcare staff members have a low sense of belonging to the network, and the lack of intermediate articulation and negotiation spaces are the main hurdles for network development. ${ }^{2}$

Another aspect to take into account is that the brief experience of the network and the innovative character of the proposal of a comprehensive healthcare network system in our country could account for the limitations observed in its operations. The concept of networking implies several aspects in addition to referral and counterreferral, such as clinical management, territorial administration, and governance; therefore, it should be highlighted that, at least in theory, the concept of the HEC network implies a healthcare network. The founding idea behind a "network hospital" means a coordinated and supplementary work among healthcare providers of the same region, even if there is a gap between the concept and the reality.

Based on the data obtained from this study and on the theoretical aspects supporting the development of a comprehensive healthcare network, immediate interventions should include:

- Creating a body for coordinating and monitoring the operations of the pediatric network.

- Establishing a "list of available pediatric services" including all of the network's providers.

- Defining the criteria for admitting, counterreferring and discharging patients from the PIMCU.

- Creating a universal medical record form for referring, counter-referring and discharging pediatric patients within the network.

Over the past years, the HEC started working towards the consolidation of the network, both at the pediatric department and the hospital management levels. Actions were taken for improving the level of knowledge and interaction between the pediatric departments in the network, including regular meetings among the heads of pediatric departments, the development of common clinical practice guidelines, a universal referral/counter-referral form, consensus on patient admission to and 
discharge from the PIMCU. In addition, training activities aimed at the network members were initiated. The HEC extended the actions taken at the Patient Management office in order to deepen the exchange between healthcare providers and started working at the different health and political decision-making levels to strengthen the network's effective management. Results from these interventions have not yet been assessed.

In one of the few experiences published about other network health systems, and similar to what has been described in our study, Maceira ${ }^{6}$ identified the main weaknesses of health networks: lack of nominalization of the population; unequal use of referral and counterreferral mechanisms; lack of human resource planning and management; an inefficient distribution of human resources and equipment; different funding mechanisms leading to service quality and staff incentives being heterogeneous and hospital managers having a varying autonomy at the time of making decisions; and lack of network coordination.

Other described experiences mainly show the misuse of resources for taking care of problems that could be solved at a lower level of care, the lack of knowledge on how the network operates, and the problems related to information continuity. ${ }^{6-8,10-14}$

\section{CONCLUSIONS}

Care exchange within the health network was mainly based on tertiary care facilities accepting referrals and on a minimum number of counterreferrals to referring facilities.

The operation dynamics between secondary care facilities and the HEC have a radial pattern. There was little knowledge about the availability of services provided by the network.

\section{Glossary}

Referral/counter-referral process: referral is when patients are referred from a facility with a lower level of care to a facility with a higher level of care, and counter-referral is when patients go through the reverse process. ${ }^{3,10}$

\section{REFERENCES}

1. Redes integradas de servicios desalud: conceptos, opciones de política y hoja de ruta para su implementación en las Américas. Washington DC: OPS; 2010.

2. Rovere, M. Redes en salud; un nuevo paradigma para el abordaje de las organizaciones y la comunidad. Ed: Secretaría de Salud PúblicalAMR, Instituto Lazarte; 1999.

3. Terraza Núñez R, Vargas Lorenzo I, Vázquez Navarrete ML. La coordinación entre niveles asistenciales: una sistematización de sus instrumentos y medidas. Gac Sanit 2006;20:485-95.

4. Plan Estratégico 2009-2012 Hospital El Cruce, Alta Complejidad en Red. Florencio Varela, Buenos Aires, Argentina: s.n. 2009-2012.

5. Terris M. Tres sistemas mundiales de atención médica. Cuadernos Médico-sociales N 14, agosto 1980. Traducido de: World Health Forum (OMS, Ginebra) 1980;1(1 y 2):76-86.

6. Maceira D. Cómo fortalecer las redes de servicios de salud. El caso de Salta. Revista del ITAES 2011;13(2).

7. Jaimovich D, and the Committee on Hospital Care and Section on Critical Care, Guidance for Clinical Rendering Pediatric Care, Admission and Discharge Guidelines for the Pediatric Patient Requering Intermediate Care, American Academy of Pediatrics. Pediatrics 2004;113:1430-3.

8. Varone G, Dussel V, Bisigniano L, Hidalgo S, et al. Estudio de la estructura y motivaciones de la demanda espontánea al Hospital dePediatría SAMIC "Prof. Dr. Juan P. Garrahan". Arch Argent Pediatr 1990;88:232-8

9. Haggerty JL, Reid RJ, Freeman GK, Starfield $\mathrm{BH}$, et al. Continuity of care: a multidisciplinary review. BMJ 2003;327:1219-21.

10. Snow V, Beck D, Budnitz T, Miller DC, et al. Transitions of care consensus policy statement: American College of Physicians, Society of General Internal Medicine, Society of Hospital Emergency Physicians, and Society for Academic Emergency Medicine. J Hosp Med 2009;4(6):364-70.

11. Pardo L, Zabala C, Gutiérrez S, Pastorini J, et al. Sistema de referencia-contrarreferencia en pediatría, Análisis de la situación en el Hospital Pediátrico del Centro Hospitalario Pereira Rossell. Rev Med Uruguay 2008;24:69-82.

12. Sansó Soberats F. Propuesta de modelo de referencia y contrarreferencia en el Sistema de Salud Cubano. Rev Cubana Med Gen Integr 1999;15:613-20.

13. López R, Gallego Machado B, Díaz Novás J. Formato recomendable para llenar la hoja de remisión médica de un paciente. Rev Cubana Med Gen Integr 2006;22(2).

14. Kripalani S, LeFevre F, Phillips ChO. Deficits in communication and information transfer between hospitalbased and primary care physicians: Implications for patient safety and continuity of care. JAMA 2007;297:831-41. 


\section{ANNEX \\ KNOWLEDGE SURVEY - PEDIATRIC HEALTH NETWORK}

Dear Colleague,

The Intermediate Medical Care Unit of Hospital El Cruce is conducting a study to evaluate how the network operates. Your opinion is important to improve the care provided to our patients; your suggestions and remarks will help us make changes and correct mistakes. For this reason, we would like you to complete this survey. The survey will be distributed among the heads of pediatric departments of the different network hospitals, so your filling in the survey implies your consent to participate.

\section{Hospital:}

Position/Responsibility

1. Have the members of your department been informed or trained in relation to how to work in a health network?
Mostly [ ]
Moderately [ ]
Little or not at all [ ]
$\mathrm{Dk} / \mathrm{Da}[]$

2. In your opinion, at what level of "network development" would you place the pediatric care network of the hospitals in the sixth sub-region?
Knowledge [ ]
Collaboration [ ]
Cooperation [ ]
Partnership [ ]
$\mathrm{Dk} / \mathrm{Da}[]$

3. In your opinion, does the network correctly interact in its different levels?

$\begin{array}{llllll}\text { Primary care-Secondary care: } & \text { Mostly [ ] } & \text { Moderately [ ] } & \text { Little [ ] } & \text { Not at all [ ] } & \text { Dk/Da [ ] } \\ \text { Secondary care-Tertiary care: } & \text { Mostly [ ] } & \text { Moderately [ ] } & \text { Little [ ] } & \text { Not at all [ ] } & \text { Dk/Da [ ] } \\ \text { Tertiary care-Secondary care: } & \text { Mostly [ ] } & \text { Moderately [ ] } & \text { Little [ ] } & \text { Not at all [ ] } & \text { Dk/Da [ ] } \\ \text { Secondary care-Primary care: } & \text { Mostly [ ] } & \text { Moderately [ ] } & \text { Little [ ] } & \text { Not at all [ ] } & \text { Dk/Da [ ] } \\ \text { Tertiary care-Primary care: } & \text { Mostly [ ] } & \text { Moderately [ ] } & \text { Little [ ] } & \text { Not at all [ ] } & \text { Dk/Da [ ] }\end{array}$

4. Based on your knowledge, indicate which sub-specialties are available at the different network hospitals:

\begin{tabular}{|c|c|c|c|c|c|c|c|c|c|c|c|c|c|c|c|c|c|c|c|c|c|}
\hline & \multicolumn{3}{|c|}{ El Cruce } & \multicolumn{3}{|c|}{ Iriarte } & \multicolumn{3}{|c|}{ Mi Pueblo } & \multicolumn{3}{|c|}{ Evita Pueblo } & \multicolumn{3}{|c|}{ Oller } & \multicolumn{3}{|c|}{ Adrogué } & \multicolumn{3}{|c|}{ Oñativia } \\
\hline & Yes & \begin{tabular}{|l|l} 
No & D \\
\end{tabular} & & les $N$ & & $\mathrm{Dk}$ & Yes & No & Dk & Yes & No & $\mathrm{Dk}$ & Yes & No 1 & $\mathrm{Dk}$ & Yes & No & Dk & Yes & $\mathrm{No}$ & $\mathrm{Dk}$ \\
\hline $\begin{array}{l}\text { Pediatric } \\
\text { cardiology }\end{array}$ & & & & & & & & & & & & & & & & & & & & & \\
\hline $\begin{array}{l}\text { Pediatric } \\
\text { heart surgery }\end{array}$ & & & & & & & & & & & & & & & & & & & & & \\
\hline $\begin{array}{l}\text { Pediatric } \\
\text { pneumonology }\end{array}$ & & & & & & & & & & & & & & & & & & & & & \\
\hline $\begin{array}{l}\text { Pediatric } \\
\text { neurosurgery }\end{array}$ & & & & & & & & & & & & & & & & & & & & & \\
\hline $\begin{array}{l}\text { Pediatric } \\
\text { neurology }\end{array}$ & & & & & & & & & & & & & & & & & & & & & \\
\hline Endoscopy & & & & & & & & & & & & & & & & & & & & & \\
\hline $\begin{array}{l}\text { Pediatric } \\
\text { gastroenterology }\end{array}$ & & & & & & & & & & & & & & & & & & & & & \\
\hline
\end{tabular}


\begin{tabular}{l|c|c|c|c|c|c|} 
El Cruce & Iriarte & Mi Pueblo & Evita Pueblo & Oller & Adrogué & Oñativia \\
\hline
\end{tabular}

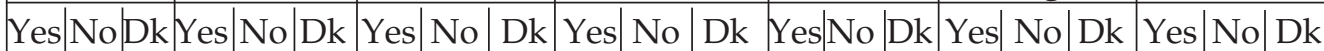

Pediatric

surgery

Pediatric

ophthalmology

Speech therapy

Psychology

Nutrition

(certified)

Physical therapy

Occupational

therapist

Rehabilitation

Genetics

Pediatric

rheumatology

Pediatric

orthopedics

Pediatric

infectious

diseases

Pediatric

endocrinology

ENT

Plastic surgery

Maxillo-facial

surgery

Other

5. Mark the correct statement with an $\mathrm{X}$, as per your opinion:

a. In relation to "counter-referring" patients from Hospital El Cruce:

\begin{tabular}{l|l|l|l|l} 
& Always & Sometimes & Occasionally & Never \\
\hline It is done in a timely manner & & & & \\
\hline $\begin{array}{l}\text { Summaries provided } \\
\text { are clear and brief }\end{array}$ & & & & \\
\hline $\begin{array}{l}\text { Inter-hospital doctor to } \\
\text { doctor communications are good }\end{array}$ & & & & \\
\hline
\end{tabular}

b. In relation to "referring" patients to Hospital El Cruce:

\begin{tabular}{l|l|l|l|l} 
& Always & Sometimes & Occasionally & Never \\
\hline It is done in a timely mann & & & & \\
\hline $\begin{array}{l}\text { Inter-hospital doctor to } \\
\text { doctor communications are good }\end{array}$ & & & & \\
\hline
\end{tabular}


414 / Arch Argent Pediatr 2013;111(5):405-411 / Original article

c. In relation to patients referred to and discharged from Hospital El Cruce :

\begin{tabular}{l|l|l|l|l} 
& Always & Sometimes & Occasionally & Never \\
\hline Discharge conditions are detailed & & & & \\
\hline $\begin{array}{l}\text { Patients receive longitudinal } \\
\text { follow-up after the hospitalization } \\
\text { according to their needs }\end{array}$ & & & & \\
\hline
\end{tabular}

6. Do you have any suggestions, information, or expectations in relation to the pediatric care provided at the network?

Please, provide a detailed description here: 